\title{
A comunicação das organizações diante de públicos, esfera pública e opinião pública: como as plataformas sociais digitais se encaixam nisso?
}

The communication of organizations towards audiences, public sphere and public opinion: how do digital social platforms handle this?

La comunicación de las organizaciones ante las audiencias, la esfera pública y la opinión pública: ¿cómo se encuadran las plataformas sociales digitales en eso?

\section{Elizabeth Saad}

- Doutora em Ciências da Comunicação, mestre e graduada em Administração de Empresas.

- Professora titular sênior da Escola de Comunicações e Artes (ECA) da Universidade de São Paulo (USP).

- Docente e orientadora em mestrado e doutorado do programa de pós-graduação em Ciências da Comunicação.

- Coordenadora do grupo de pesquisa COM+.

- Autora de artigos, livros e capítulos de livros nos campos da comunicação e do jornalismo digital.

- Palestrante internacional e membro do review team do periódico Digital Journalism.

- E-mail: bethsaad@usp.br; bethsaad@gmail.com 


\section{Resumo}

Examinamos, por meio de abordagem conceitual, a caracterização do discurso e das ações de comunicação das organizações diante de uma esfera pública híbrida na qual a opinião pública adquire um status paradoxal de autonomia de expressão estando, simultaneamente, sob o determinismo algorítmico das ambiências para expressão de opinião. Iniciamos a discussão pelo entendimento da esfera pública híbrida constituída por uma miríade de ambiências que abrigam redes de sociabilidade; consideramos os fatores intervenientes que impactam a comunicação das organizações - os discursos mediados por modulações algorítmicas e também por influenciadores; e concluímos com reflexões sobre os relacionamentos com públicos, audiências e a formação de opinião que, a despeito de propósitos claros da organização, são impactados por processos de desinformação. Como suporte conceitual, além de material produzido pela autora, tomamos as referências clássicas de Papacharissi (2002), Boyd e Baym (2012), Livingstone (2015), Caplan e Boyd (2016).

PALAVRAS-CHAVE: OPINIÃO PÚBLICA・REDES SOCIAIS • COMUNICAÇÃO ORGANIZACIONAL・DIGITALIZAÇÃO.

\section{Abstract}

We utilize a conceptual approach to characterize the discourse and communication actions of organizations in the face of a hybrid public sphere, where public opinion acquires a paradoxical status of autonomy of expression while simultaneously subjected to the algorithmic determinism of environments to express one's opinion. We started the discussion by understanding the hybrid public sphere constituted by a myriad of environments that shelter networks of sociability; we consider the intervening factors that impact the communication of organizations - discourses mediated by algorithmic modulations and by influencers; and we conclude reflecting upon relationships with audiences and the formation of opinions that, despite clear organization purposes, are impacted by disinformation processes. As a conceptual support, in addition to material produced by the author, we follow the classic references of Papacharissi (2002), Boyd \& Baym (2012), Livingstone (2015), Caplan \& Boyd (2016).

\section{KEYWORDS: PUBLIC OPINION・SOCIAL NETWORKS・ORGANIZATIONAL COMMUNICATION・DIGITALIZATION.}

\section{Resumen}

Desde un abordaje conceptual, analizamos la caracterización del discurso y de las acciones comunicativas de las organizaciones frente a una esfera pública híbrida en la cual la opinión pública adquiere un estatus paradójico de autonomía de expresión al mismo tiempo que se encuentra bajo el determinismo algorítmico de los entornos de expresión de opinión. Comenzamos con la discusión de la comprensión de la esfera pública híbrida que se constituye de una miríada de ambientes que abarcan redes de sociabilidad; luego, consideramos los factores intervinientes que impactan en la comunicación de las organizaciones los discursos mediados por modulaciones algorítmicas y también por influenciadores -; y concluimos con reflexiones sobre las relaciones con las audiencias, el público y la formación de opiniones que, a pesar de claros propósitos de la organización, se ven impactadas por procesos de desinformación. El marco conceptual utilizado, además del material elaborado por la autora, fueron las fuentes clásicas de Papacharissi (2002), Boyd y Baym (2012), Livingstone (2015) y Caplan y Boyd (2016). 
$\mathrm{R}$ efletir sobre opinião pública em contextos da sociedade digitalizada é tarefa complexa diante da multiplicidade de correlações que o tema incita. Questões básicas surgem logo de início: sobre quais públicos falamos? Esfera pública nas ambiências digitais é realmente pública? Ambiências digitais podem ser consideradas como espaço público? A mediação algorítmica instalada na governança das ambiências digitais interfere na formação da opinião pública? Como a comunicação das organizações se posiciona diante de seu público?

Se adentrarmos na arena das organizações, a complexidade se amplia e os questionamentos seguem no mesmo rumo, pois o alcance de atuação das empresas - seja em termos de públicos, seja em termos de poder discursivo - possui diferentes configurações vinculadas às especificidades de cada entidade.

E, ao inserirmos todos os questionamentos anteriores no panorama ainda mais amplo do processo comunicativo contemporâneo, temos um adicional conjunto de questões por discutir, já que há que se considerar as mediações e os processos de midiatização instalados no tecido social conectado em rede, além de considerar sobre qual esfera falamos diante de uma hibridização de tempos e espaços.

Temos tratado do tema esfera-opinião pública no meio digital já há algum tempo, caracterizando a cena cibercultural (Saad Corrêa, 2010); buscando uma caracterização de um ciberespaço híbrido pautado pelo determinismo da governança das plataformas (Saad Corrêa, 2014); analisando o posicionamento do campo da comunicação digitalizada como elemento central e transversal nos processos de sociabilidade (Saad Corrêa, 2015); indicando o impacto dos processos de plataformização em escala pública (Saad Corrêa, 2020) e discutindo as transformações emergentes dos relacionamentos com públicos (Saad Corrêa, [2021?]).

É a partir deste conjunto de reflexões associado a referencias da literatura (Papacharissi, 2002; Boyd; Baym 2012; Livingstone, 2015; Caplan; Boyd, 2016) que delimitamos nossa abordagem com os seguintes pressupostos: a) a esfera pública contemporânea transita simultaneamente por diferentes ambiências; b) por consequência, a opinião pública decorrente assume múltiplas configurações determinadas pela ambiência onde se instala; c) a governança algorítmica, que define as diferentes plataformas de redes sociais, atua como elemento de modulação da opinião pública, impactado a comunicação de organizações; d) esfera e opinião pública assumem uma configuração híbrida por conta de seus trânsitos em ambiências quando conectadas às redes digitais.

Considerando tais pressupostos, este artigo examina a caracterização do discurso e das ações de comunicação das organizações diante de uma esfera pública híbrida, em que a opinião pública adquire um status paradoxal de autonomia de expressão enquanto, simultaneamente, sob o determinismo algorítmico das ambiências para expressão de opinião.

Para tanto, partimos do entendimento da esfera pública híbrida constituída por uma miríade de ambiências que abrigam redes de sociabilidade; consideramos os fatores intervenientes que impactam a comunicação das organizações - os discursos mediados por modulações algorítmicas e também por influenciadores; e concluímos com reflexões sobre os relacionamentos com públicos, audiências e a formação de opinião que, a despeito de propósitos claros da organização, são impactados por processos de desinformação. 


\section{AS AMBIÊNCIAS DE UMA ESFERA PÚBLICA HÍBRIDA}

Diferentes autores discutem a rede digital como um espectro: 0 ideário das utopias às distopias inerentes de um espaço de conexão, que colocam no mesmo patamar um imenso volume de dados e informações - agora denominado big data; as diferentes possibilidades - delimitadas por aspectos sociais, econômicos e culturais - de acesso a esse manancial de bits; as desequilibradas formas de relacionamento, transações e discursos mediados pelo denominado capitalismo de plataforma', seus valores e as evidentes diferenças de acesso e participação dos públicos ao mundo das ambiências.

Papacharissi (2002, p.20, tradução nossa) considera o ciberespaço como um espaço público e privado ao mesmo tempo "que oferece terreno fértil para a recorrência das velhas fricções entre identidade privada e coletiva, entre o individual e o comunitário. [...] ampliando canais de comunicação sem, contudo, afetar radicalmente a própria comunicação.". Para a autora, a esfera virtual consiste num conjunto de múltiplas microesferas culturalmente fragmentadas que ocupam um espaço comum: o ciberespaço - ou melhor, a rede digital em conexão.

Um cenário que encontra eco em Saad Corrêa (2014, p.218) ao avaliar o indivíduo conectado que se vê diante de "uma sucessão de ambiências que, além das trocas, diálogos e interações, colocam em campo público a exposição do indivíduo e trazem questões como individualidade, identidade e subjetividade tradicionalmente consideradas como da ordem da esfera privada". Assim, não podemos caracterizar opinião pública como um corpo único e coeso; pelo contrário. Consequentemente, ações de comunicação precisam levar em conta todas as nuances dessas ambiências. Exemplificando, a imagem de uma marca e a opinião pública sobre ela dependem de seus percursos pelas ambiências digitais e das formas discursivas utilizadas conforme o perfil de cada ambiência.

Retomando Saad Corrêa (2019, p.155):

O que temos como fato decorrente do digital é que "públicos" e "opinião pública" circulam simultaneamente por ambiências segmentadas, desterritorializadas e controladas (mediadas, tendenciadas e moduladas) por plataformas sociais digitais que definem, por meio da modulação das relações, todo um comportamento social e comunicativo do coletivo. Consequente e naturalmente, as instancias institucionais e econômicas atuam no mesmo diapasão, todos num processo de meta e retroalimentação de dados sobre si.

A partir da ideia de multi-ambiências como locus das esferas (públicas) em redes digitais, buscamos um enquadramento adicional deste cenário por meio do conceito de heterotopia, originalmente cunhado por Michel Foucault em uma entrevista radiofônica de 1966. Para ele, o termo heterotopia significa "outro espaço" externo ao self"onde ocorre a erosão de nossas vidas, de nossa história e de nosso tempo. Um espaço que nos atormenta e consome" (Foucault; Miskowiec, 1986 apud Lee; Wei, 2020). 0 ponto central da proposta de Foucault relaciona as heterotopias a expressões da cultura de um dado contexto social, não importando se registradas no cotidiano físico ou nesses "outros espaços".

Um olhar amplo para a ideia foucaultiana de heterotopia nos apoia ao caracterizar as multi-ambiências da esfera pública conectadas e as plataformas sociais ali instaladas como exemplos de "outros espaços" ou como um "placeless place" (lugar/ não-lugar) aonde se dão os discursos organizacionais. Reforçando, Boyd e Baym (2012) caracterizam as mídias sociais como

1 Expressão cunhada pela pesquisadora Jose Van Djick, da London School of Economics e também por Srnicek Nick que se refere à inextricável relação entre plataformas online e estruturas societais quetêm se tornado quase inteiramente dependentes das infraestruturas digitais providenciadas pelas cinco grande empresas de plataformas dos Estados Unidos: Google (Alphabet), Amazon, Facebook Apple e Microsoft. Eles arquitetaram suas infraestruturas de acordo com os mecanismos de plataforma definidas como dataficação, mercantilização e seleção algorítmica. 
um espaço público engendrado por meio de tecnologias de conexão pelas quais emerge um imaginário coletivo resultante da combinação de tecnologias, pessoas e práticas. As autoras colocam em questão as relações entre público/privado e audiência/público.

Essas caracterizações das mídias sociais - um espaço público conectado e heterotópico - possibilitam uma conexão com a atividade comunicativa tanto de organizações quanto de indivíduos. As plataformas sociais digitais oferecem o espaço público de visibilidade e de discursos por meio de um conjunto de características que permitem a repetição e a perenidade de conteúdos, sua replicação, escalabilidade e busca. Um não-lugar adequado à produção de discursos organizacionais e dos relacionamentos decorrentes.

A construção da opinião pública decorrente de um discurso organizacional que trafega na miríade heterotópica das plataformas faz com que os produtores dos discursos e relacionamentos - comunicadores e marcas - desenvolvam suas atividades comunicativas levando em conta affordances ${ }^{2}$ proporcionadas por tais espaços de forma a resultar relacionamentos eficazes com audiências/públicos.

0 estudo elaborado por Lee e Wei (2020) identificou, por meio do método de pesquisa-ação junto às principais plataformas sociais digitais atualmente em uso - Facebook, Instagram, Twitter e YouTube -, as affordances por elas oferecidas que oferecessem aos usuários atividades desvinculadas do meio físico e que pudessem conduzir a um trânsito tipicamente placeless na rede e que produzissem manifestações da cultura contemporânea. Os pesquisadores identificaram as hashtags, os links de compartilhamento, o perfil do usuário, o recurso \#retrocesso (muitas vezes identificado como \#tbt), as transmissões ao vivo e as configurações de privacidade de cada plataforma como intervenções que impactam os relacionamentos e os discursos na ambiência e forjam uma cultura de conexão.

Considerando que cada plataforma social digital, ou seja, uma ambiência placeless, traz conjuntos específicos de affordances, a atividade do comunicador para a construção e perenização de seus discursos e relacionamentos deverá estar ancorada em estratégias de comunicação que desenhem a visibilidade da marca nas diferentes plataformas e explorem eficazmente as respectivas affordances.

\section{MODULAÇÃO ALGORÍTMICA, OPINIÃO PÚBLICA E AS REDES DE INFLUÊNCIA}

Ao assumirmos o hibridismo da esfera pública e suas fragmentações derivadas das múltiplas plataformas sociais digitais nela estabelecidas, temos que assumir, também, sua não neutralidade e não equidade. Em termos práticos, a grande arena digital não oferece as mesmas informações, os mesmos conteúdos e as mesmas formas de relacionamento para quem está conectado na rede.

Uma sucessão de fatores intervenientes atua contra uma circulação de conteúdos informativos igualitária. Tais fatores atuam, sim, favorecendo os diferentes interesses econômicos e políticos dos proprietários de cada plataforma social digital.

Poderíamos argumentar que a esfera pública hibrida não se restringe às ambiências das plataformas sociais digitais, e que existe na rede um volume significativo de entidades que se fazem visíveis fora das plataformas - a exemplo da grande maioria dos meios jornalísticos, organizações não governamentais, instituições da sociedade e do governo, entre outras. Ocorre que a 
outra ponta do fluxo de acesso à rede - o público (audiência, usuários) - conecta-se ao espaço virtual preferencialmente por meio de uma plataforma como primeiro locus de acesso, e, mais especificamente, por meio do Google para, posteriormente, alcançar o conteúdo de seu interesse.

A pesquisa TIC Domicílios 2019, realizada pelo Comitê Gestor da Internet no Brasil (Cetic), indica que o país tem 134 milhões de brasileiros conectados e, desses, $96 \%$ acessa a rede por meio de dispositivos móveis. 0 Google é o site mais acessado no país, seguido de YouTube, Facebook e Globo.com. Corroborando, o Digital News Report 2020, publicado pela Universidade de Oxford em conjunto com o Reuters Institute for Journalism, aponta que 67\% dos pesquisadores acessa notícias e informações por meio das plataformas sociais.

Esses indicadores nos levam a concluir que a esfera pública brasileira tem os pés fincados prioritariamente no espaço digital das plataformas sociais digitais. É aqui que os fatores intervenientes entram em ação: mediação e modulação algorítmica, mecanismos de automação (robôs) na produção e distribuição de conteúdos, além de formas de controle e disputa do poder na formação da opinião coletiva.

Caplan \& Boyd argumentam que os algoritmos - instrumentos técnicos que gerenciam o uso e a visibilidade das plataformas sociais digitais, são sistemas opacos e funcionam como influenciadores e até mesmo como condutores daquilo que deve ser visto por cada tipo de usuário da plataforma. Para as pesquisadoras:

"algoritmos são utilizados para classificar, filtrar e priorizar conteúdos baseados nos valores internos do sistema e nas preferencias e ações dos usuários [...] e podem ser usados para insuflar um assunto de forma a fazê-lo mais popular alterando a percepção para a opinião pública." (Caplan; Boyd, 2016, p.5-8, tradução nossa).

O professor Sergio Amadeu da Silveira denomina esse processo de modulação algorítmica como "[...] um processo de controle da visualização de conteúdos, sejam discursos, imagens e sons. Elas não criam discursos, mas possuem sistemas algorítmicos que distribuem os discursos criados pelos usuários, sejam corporações sejam pessoas." (Sousa etal., 2018, p. 38). Para 0 pesquisador, a modulação encurta a realidade e a multiplicidade dos discursos a serviço do marketing e da comunicação de seus clientes, acelerando a relação, por exemplo, entre marca e consumidor, criando vínculos de afeto e fidelidade entre eles a partir de funcionalidades como "curta" ou "comente", possibilitando a absorção mais eficaz do discurso de marca e potencializando algum tipo de transação.

Portanto, referenciando-nos em Saad Corrêa, (2020), ao considerarmos que a construção de público e de opinião pública no contemporâneo digital decorre da ação performada pelas plataformas sociais digitais para conectar discursos e redes, há que se ressignificar o papel do profissional de comunicação nesse cenário. É desejável uma atuação ativa, interveniente e estratégica, de forma a equalizar a dupla mediação entre público (consumidor ou não), discurso de marca e de imagem e modulação da plataforma.

Importante destacar que, em meio ao processo algoritimizado das plataformas sociais digitais, trafegam entidades/indivíduos que operam de forma autônoma, denominados "influenciadores" e que carreiam para si enormes contingentes de tráfego os seguidores. Tais elementos constituem-se, atualmente, hubs de agregação da formação da opinião e de vantagens econômicas.

Segundo a pesquisadora e professora Issaaf Karhawi (2019), 
[...] os influenciadores digitais, blogueiros, youtubers ou creators são produtores de conteúdo que se valem da reputação que constroem na rede junto a seus públicos para atuar ao lado de marcas na promoção de produtos. Esse tipo de parceria comercial tem sido uma estratégia comum no Brasil, tanto em estratégias de Relações Públicas quanto em ações de mídia paga.

Essas redes autônomas de influência atuam sob as lógicas de modulação das plataformas e gerenciam seus perfis ou microesferas de atuação, constituindo-se em mais um elemento de mediação na formação da opinião pública. 0 item a seguir explora com mais detalhes esse processo.

\section{A ATIVIDADE COMUNICATIVA DIANTE DE UMA OPINIÃO PÚBLICA IN(DES)INFORMADA}

Aqui adentramos mais diretamente a atividade de comunicação nas organizações, ancorada num espaço público híbrido, modulado, controlado e influenciado/tendenciado por fatores em sua maioria externos à organização.

Estratégias de comunicação, discursos, conteúdos e relacionamentos são algumas das atividades mais sensíveis da organização em sua atuação na esfera pública híbrida. Simultaneamente, tal atuação submetida à cultura modulada, tem potencial de, alcançada a audiência, passar por desvios de sentido. significado, desinformação e até mesmo crises de imagem para uma organização. Uma linha tênue separa os campos³.

Assumimos, a partir dos tópicos anteriores, que a participação das organizações na esfera pública híbrida se dá, primordialmente, por meio das plataformas sociais digitais. Tais ambiências constituem-se como canais, seja de embaixadores, seja de detratores de marcas, corporações e personalidades, abrindo espaço para todo tipo de expressão, defesas e/ou combate de causas, produtos, serviços e pessoas. Também se constituem em canais da organização para dar visibilidade a suas marcas e estabelecer interações com a audiência: posts no Instagram, fanpage no Facebook, canal de vídeo no YouTube, criação de grupos no WhatsApp, uso de sistemas de publicidade digital, uso de social bots ${ }^{4}$, dentre outras modalidades. Dessa forma, as organizações se veem constantemente num espaço onde ocorrem ações sucessivas de mediação e midiatização a exemplo de debates, embates, elogios, necessidades, reforços, persuasões, ocorrendo em tempo real, exigindo um esforço significativo de monitoramento, atenção e alerta. Falamos aqui de governança da presença de uma organização nas ambiências digitais.

Um breve e não sistemático levantamento (Rodríguez-Fernández, 2019; Wiesenberg; Tench, 2019; Krafft; Donovan, 2020; Lock; Ludolf, 2020; Bowers; Zittrain, 2020; Jahang etal., 2020) sobre o tema na literatura internacional recente aponta, a partir da ideia da necessária governança, alguns aspectos importantes que indicamos a seguir:

- práticas de manipulação de dados são recorrentes nas ambiências digitais e são disponíveis - cada grupo a seu modo, para todos os "habitantes" de uma plataforma. Filtragem algorítmica, remixagem de conteúdos especialmente alterando vozes e discursos de representantes formais de uma organização, uso de fazendas de clickse social bots são bastante comuns. Resulta para a organização numa rápida descontextualização de seus discursos que, se não monitorada e debelada, tem o potencial de crise e prejuízos de imagem;

- o design das plataformas sociais digitais centraliza o controle do conteúdo que trafega em sua ambiência e, ao mesmo tempo, a partir do acesso a elas por parte de usuários os devolvem para a rede como um todo de forma aleatória -

3 Importante relembrar que o cenário aqui enfatizado para o mundo digital já existia por meio de outras mídias desde muito antes da digitalização da sociedade.

4 Um bot social é um agente em código informático que se comunica de maneira mais ou menos autônoma nas mídias sociais, geralmente com a tarefa de influenciar o curso da discussão e/ou as opiniões de seus leitores. Está relacionado aos chatbots, mas na maioria das vezes usa apenas interações bastante simples ou nenhuma reatividade. 
dado seu design descentralizado, disseminando de forma descontrolada o conteúdo. Com isso, a organização pode não ter garantido o correto sentido de suas mensagens;

- aspectos político-ideológicos também têm o potencial de impactar os discursos organizacionais a partir do princípio de "sabedoria das multidões", quando ocorre a agregação de vozes similares (bolhas informativas ou de opiniões, crenças e valores), formando uma opinião ou visão que pode ser diversa daquela da organização. Exemplos desse fenômeno são vários quando nos referimos a boicotes contra marcas por conta das visões de seus detentores/proprietários;

- 0 uso de sistemas programáticos de publicidade digital - a exemplo do Google AdSense, se não bem desenhado pela marca que compra tais espaços publicitários, tem o potencial de colocar seus anúncios em ambiências que não têm qualquer relação com sua imagem; a frase de Bowers e Zittrain (2020) esclarece: "As plataformas dominantes da Internet de hoje se baseiam na noção de que pessoas sem audiência podem, através de uma bola de neve de relações serem atraídas para ela se tiver algo atraente a dizer";

- a midiatização profunda ${ }^{5}$ faz com que tudo o que circula nas plataformas se transforme em dados desvinculados de seu conteúdo original, podendo ser utilizado em outros contextos. Com isso, a construção social que sustenta a opinião pública deixa de ser exclusiva ao humano e passa a ter algoritmos como partícipes de discursos. As organizações precisam estar atentas ao fenômeno, já que, além de atuar como escuta de sua audiência, passam a ter humanos de algoritmos como parceiros de suas mensagens;

- monitorar a desinformação e mensagens midiatizadas vinculadas a uma organização e suas marcas passa a ser uma atividade estratégica e crítica da área de relações públicas e comunicação. 0 uso de práticas de verificação é fundamental para que a empresa se antecipe diante de crises eventuais, seja por verificações cruzadas de fontes, seja pelo controle interno de seus discursos, seja pelo acompanhamento formal e contínuo de sua presença nas ambiências digitais.

\section{REFLEXÕES COMO CONSIDERAÇÕES FINAIS}

Expusemos um cenário bastante complexo no qual as organizações contemporâneas atuam e onde necessitam estar de forma estratégica e atenta. Autores da filosofia e da história, a exemplo de Yuval Noah Harari (2018) e Buyng-chul Han (2018), são enfáticos ao discutir o nosso viver contemporâneo irremediavelmente digitalizado, mas incorporando ao mesmo tempo todo um conjunto de transformações do que seja privacidade, robotização do humano, relações pervasivas, vigilância, entre outros aspectos.

A opinião pública contemporânea é e será reflexo desse cenário. A comunicação das organizações seguirá em postura resiliente, consciente de que não existem modelos prontos, de que cada uma deverá buscar adequações à sua identidade e que não existem condições sociotécnicas e comunicativas para "controlar" a opinião pública, que são múltiplas e entidades autônomas.

Surgem aqui alguns pontos sensíveis e de atenção para as organizações nas ambiências digitais.

Repensar, em moto contínuo, o planejamento e a efetivação dos processos comunicativos, levando em conta aspectos como as transformações do trabalho e dos modos de produção e consumo na sociedade que afetam diretamente os modos de mediação e midiatização vigentes e, por consequência, o trabalho do comunicador.

5 Midiatização é conceituada por Mediatization Couldry and Hepp (2017) como um meta-processo de ampliação da penetração das mensagens na rede por meio de tecnologias e sistemas algorítmicos. 
Na mesma linha, efetivar de planos de contingência para eventuais crises e campanhas de desinformação são fundamentais. Evitar crises requer competências atualizadas das equipes de comunicação, especialmente com relação a procedimentos de debunking ${ }^{6}$ e checagem cruzada de discursos.

Um outro ponto importante refere-se à intensidade do uso de ferramentas e novos atores do ecossistema - a exemplo de influenciadores/YouTubers e suas respectivas adequações à proposta comunicativa e à audiência desejada. Há que se considerar as melhores formas e instrumentos de proximidade com o público-alvo que tenham aderência ao plano e à imagem de marca. É preciso levar em conta que, nas ambiências digitais, ritmos e tempos são diferentes do mundo analógico e, portanto, conteúdos e respectivos impactos nos públicos tornam-se exponenciais e potencialmente geradores de crises, exigindo uma ação imediata e pré-planejada dos comunicadores.

\section{REFERÊNCIAS}

BOWERS, John; ZITTRAIN, Jonathan L. Answering impossible questions: content governance in an age of disinformation. Harvard Kennedy School Misinformation Review, Cambridge, MA, v.1, n.1, p.1-8, 2020. doi:10.37016/mr-2020-005

BOYD, Danah; BAYM, Nancy K. Socially mediated publicness: an introduction. Journal of Broadcasting \& Electronic Media, Abingdon, v.56, n.:3, p.320-329, 2012. doi: 10.1080/08838151.2012.705200

CAPLAN, Robyn; BOYD, Danah. Who controls the public sphere in an era of algorithms? Mediation, automation, power. Data and Society, New York, 13 maio 2016. Disponível em: https://datasociety.net/wp-content/uploads/2016/05/ MediationAutomationPower_2016.pdf. Acesso em: 23 out. 2020.

HAN, Byung-chul. No enxame: perspectivas do digital. São Paulo: Companhia das Letras, 2018.

HARARI, Yuval Noah. 21 Lições para o século 21. São Paulo: Companhia das Letras, 2018.

KARHAWI, Issaaf Santos. Crises geradas por influenciadores digitais: propostas para prevenção e gestão de crises. In: CONGRESSO BRASILIERO CIENTÍFICO DE COMUNICAÇÃO ORGANIZACIONAL E DE RELAÇÕES PÚBLICAS, 13., 2019, São Paulo. Anais [...]. São Paulo: Faculdade Cásper Líbero, 2019. Disponível em: http://abrapcorp.org.br/site/manager/arq/(cod2_22771) IssaafKarhawi_GT6_Abrapcorp2019.pdf. Acesso em: 23 out. 2020.

KRAFFT, Peaks; DONOVAN, Joan. Disinformation by design: the use of evidence collages and platform filtering in a media manipulation campaign, Political Communication, Abingdon, v.37, n.2, p.194-214, 2020. doi: 10.1080/10584609.2019.1686094LEE

LEE, Kate Sangwon; WEI, Huaxin. Social media as heterotopia: applying Foucault's concept to heterotopia to analyze interventions in social media as a networked public. Korean Society of Design Science, Seongnam, v.33, n.2, p.5-17, 2020. doi: 10.15187/adr.2020.05.33.2.5

LIVINGSTONE, Sonia. On the relation between audiences and publics. In: LIVINGSTONE, Sonia (ed.). Audiences and publics. when cultural engagement matters for the public sphere. Bristol: Intellect Books, 2005. p.17-41. Disponível em: http://eprints. Ise.ac.uk/archive/00000437. Acesso em: 23 out. 2020.

6 Termo bastante utilizado no campo jornalístico para expressar a atividade de desconstrução e desmentidos sobre uma informação falsa. 
LOCK, Irina; LUDOLF, Ramona. Organizational propaganda on the internet: a systematic review. Public Relations Inquiry, Thousand Oaks, v.9, n.1, p.103-127. doi: 10.1177/2046147X19870844

PAPACHARISSI, Zizi. The virtual sphere: the internet as a public sphere. New Media and Society, Thousand Oaks, v.4, n.1, p.9-27, 2002. doi:10.1177/14614440222226244

RODRÍGUEZ-FERNÁNDEZ, Leticia. Disinformation and organizational communication: a study of the impact of fake news. Revista Latina de Comunicación Social, Tenerife, n.74, p. 1714-1728, 2019. doi: 10.4185/RLCS-2019-1406en

JAHNG, Mi Rosie; LEE Hyun-min; ROCHADIAT; Annisa. Public relations practitioners' management of fake news: exploring key elements and acts of information authentication. Public Relations Review, Amsterdam, v.46, n.2, 2020.doi: 10.1016/ j.pubrev.2020.101907

SAAD CORREAA, Elizabeth. A plataformização das relações sociais: reflexões sobre a ressignificação da atividade comunicativa. In: FARIAS, Luiz Alberto de; LEMOS, Else; REBECHI, Claudia Nociolini (org.). Opinião pública, comunicação e organizações: convergências e perspectivas contemporâneas. São Paulo: Abrapcorp, 2020. p.152-163.

SAADCORREA, Elizabeth. Centralidade, transversalidade e resiliência: reflexões sobre as três condições da contemporaneidade digital e a epistemologia da Comunicação. In: CONGRESSO IBERO-AMERICANO DE COMUNICAÇÃO, 14., 2015, São Paulo. Anais [...]. São Paulo: Universidade de São Paulo, 2015.

SAAD, Elizabeth. Comunicação organizacional e transformação digital: novos cenários, novos olhares. [S. l.: S. n.], [2021?]. No prelo.

SAAD CORRÊA, Elizabeth. Fragmentos da cena cibercultural: a transdisciplinaridade e o "não conceito". Revista USP, São Paulo, n.86, p.6-15, 2010. doi: 10.11606/issn.2316-9036.v0i86p6-15

SAAD CORRÊA, Elizabeth. Nem público, nem privado: o determinismo das práticas de redes sociais na configuração de um ciberespaço híbrido. In: SOUSA, Mauro Wilton de; SAAD CORREAA, Elizabeth (org.). Mutações no espaço público contemporâneo. São Paulo: Paulus, 2014.

SOUZA, Joyce; AVELINO, Rodolfo; SILVEIRA, Sergio Amadeu da (org.). A sociedade de controle: manipulação e modulação nas redes digitais. São Paulo: Hedra, 2018.

WIESENBERG, Markus; TENCH, Ralph. Deep strategic mediatization: organizational leaders' knowledge and usage of social bots in an era of disinformation. International Journal of Information Management, Amsterdam, v.51, 2020. doi: 10.1016/ j.jinfomgt.2019.102042

Artigo recebido em 08.10.2020 e aprovado em 08.10.2020. 